\title{
Genome Mutation Revealed by Artificial Hybridization between Chrysanthemum yoshinaganthum and Chrysanthemum vestitum Assessed by FISH and GISH
}

\author{
Magdy Hussein Abd El-Twab ${ }^{1}$ and Katsuhiko Kondo ${ }^{2}$ \\ ${ }^{1}$ Department of Botany and Microbiology, Faculty of Science, Minia University, El-Minia 61519, Egypt \\ ${ }^{2}$ Laboratory of Plant Genetics and Breeding Research, Department of Agriculture, Faculty of Agriculture, \\ Tokyo University of Agriculture, Funako, Kanagawa, Atsugi 1737, Japan
}

Correspondence should be addressed to Katsuhiko Kondo, k3kondo@nodai.ac.jp

Received 21 September 2011; Revised 7 December 2011; Accepted 21 December 2011

Academic Editor: Jaume Pellicer

Copyright ( $) 2012$ M. H. Abd El-Twab and K. Kondo. This is an open access article distributed under the Creative Commons Attribution License, which permits unrestricted use, distribution, and reproduction in any medium, provided the original work is properly cited.

\begin{abstract}
Present study has been done to investigate artificial interspecific crossability between Japanese Chrysanthemum yoshinaganthum $(2 n=36)$ and Chinese $C$. vestitum $(2 n=54)$, which were cultured in vitro and in vivo and characterization of their artificial hybrid chromosomes and type of changes assessed by FISH and GISH. GISH was applied by using biotin-labeled total genomic DNA probe of C. vestitum, which were mixed with blocking DNA of C. yoshinaganthum. Approximately 18 yellow-green colored chromosomes of $C$. vestitum were detected by the probe, approximately 18 yellow-red- mixed colored chromosomes could be common chromosomes of the two species, and nine chromosomes were relatively red of Ch. yoshinaganthum that were not detected by the probe. The expected average of FISH six signals of $5 \mathrm{~S}$ rDNA sites and ten of $45 \mathrm{~S}$ rDNA were observed on the chromosomes of three and six hybrid plants, respectively. Multicolor FISH signals showed unexpected average of seven and 14 yellow signals of $5 \mathrm{~S}$ rDNA sites on seven and thirteen chromosomes simultaneous with ten and 11 red signals of 45S rDNA sites on ten and 11 chromosomes which were detected by the probes respectively. FISH mapping of the 5S rDNA at terminal sites was detected in hybrid chromosomes, for the first time. Yellow-color signals of the telomeres were detected by the biotin-labeled probe of the PCRamplified telomeric probe in interphase and terminal sites in metaphase. All chromosomes that showed terminal signals except four chromosomes showed subterminal sites of telomeres indicating the presence of translocations.
\end{abstract}

\section{Introduction}

Chrysanthemum yoshinaganthum ( $2 n=36$, tetraploid) is endemic to Japan while C. vestitum $(2 n=54$, hexaploid $)$ is endemic to China. Studies on origin and chromosome constitutions of the native Japanese and Chinese species of Chrysanthemum sensu lato may contribute to satisfactory phylogenetic and taxonomic treatment of species relationships and the constitution and breeding cultivars. The Japanese and Chinese Chrysanthemum may be closely related to each other, make cross-hybrids, and perform a polyploid series, which plays an important role in chromosome evolution and would even perform introgressive hybridization in the nature [1-3]. In plant evolutionary studies and breeding, there is often a need to discriminate between the genomes of closely related taxa and to identify ancestors [4-9]. Since Chrysanthemum species has a self-incompatible breeding system, crosses between closely related or unrelated individuals would be unsuccessful, and, thus, in genetics, little is known in the species of the genus [10]. Therefore chromosome evidences of Chinese and Japanese species of Chrysanthemum should be compared to justify and clarify the cytogeographical disjunct and evolutionary concepts [1]. Some chromosome analyses in Japanese and Chinese Chrysanthemum and its allied genera have been carried out extensively (e.g., $[1,5,11-16])$. Several cross hybridizations between diploid and high-ploid species of Chrysanthemum were made by the artificial cross-pollination for chromosome and genome analysis (e.g., $[5,17,18])$. 
In higher eukaryotes, rDNAs are organized into two distinct gene classes of the major rDNA cluster encoding $45 \mathrm{~S}$ rDNAs, and the minor rDNA cluster encoding 5S rDNA. The minor rDNAs are usually found in loci that are separate from those of the major rDNAs and, unlike major rDNA, the minor rDNA is not involved in the nucleolus formation [19-22]. Another highly conserved sequence is found at the physical ends of chromosomes of nearly most of plant species. Multiple copies of a motif similar to the seven nucleotide unit TTTAGGG are added by an enzyme, telomerase, incorporating an RNA template, and function in stabilizing the chromosome ends and enabling semiconservative replication of the DNA up to the telomerase-added region [23].

As a pioneer among molecular cytogenetic techniques, FISH allows the identification of specific sequences in a structurally preserved cell, in metaphase or interphase. This technique, based on the complementary double-stranded nature of DNA, hybridizes labelled specific DNA (probe). The probe, bound to the target, will be developed into a fluorescent signal. FISH is a valuable method for studying the chromosomal distribution of DNA sequences and copy numbers at different sites, and to follow evolutionary changes in their physical organization in the genome [24]. FISH makes chromosomes of plant species providing the information of molecular characters of nucleolar organizing region (NOR) [25]. Several molecular evidences indicated that $45 \mathrm{~S}$ rDNA is located on NOR-bearing chromosomes [4, 5, 26-28]. FISH mapping of rDNA would be a simple and effective way to characterize diverse collections of germplasm materials and breeding lines correctly. Investigating the number and location of rDNA loci is important to gain a better understanding of evolution and phylogeny of various species in higher plant $[7,20,22,28-30]$. In plants, physical localization of the tandemly repeated genes as $5 \mathrm{~S}$ rDNA, $45 \mathrm{~S}$ rDNA, and Arabidopsis type of telomere repeats has provided a group of valuable chromosome landmark markers. The classes of rDNA and telomeres are a major type of repetitive sequence in the higher plant genome. The chromosomal localization of the 5S, 45S rDNA, and telomere repeats via FISH in the chromosome complements of several species in Chrysanthemum sensu lato was reported $[3,6,7,16,20,21$, 26-28, 31-34].

The technique of genomic in situ hybridization (GISH) has been useful in identification of parental genomes and determination of levels and incorporation positions of alien chromatin in interspecific and intergeneric plant hybrids (e.g., $[6,18,30,32,33,35-43])$.

This research is one of series that had the following objectives: (1) to investigate the interspecific cross-ability between the Japanese and Chinese species in Chrysanthemum sensu lato, (2) intergenomic characterization and the type of changes in the rDNA and telomere loci on the chromosome complement of the hybrids that resulted after hybridization of the species, (3) homology of the two parental chromosome complements, and (4) to determine whether the prevalence of genomic changes could start within the first generation. Therefore, FISH and GISH were applied on the chromosomes of $\mathrm{F}_{1}$ hybrid between C. yoshinaganthum and C. vestitum.

\section{Materials and Methods}

2.1. Cross-hybridization. Artificial cross by hand pollination was made in the forenoon of a fine day between Ch. yoshinaganthum and Ch. vestitum during the flowering seasons of the species. The method followed Tanaka et al. [12]. The disc flowers of newly blooming capitula from the maternal plant were sprayed with distilled water from an atomizer. After drying the wet flowers, their stigma was artificially pollinated with pollen from the paternal plants. Each capitulum was covered with paper bag and labeled. Subsequently, the stigma of newly blooming disc flowers was constantly cut off to prevent further pollination.

2.2. Aseptic Culture of Seeds. Twelve best-ripen achenes were sown and germinated in vitro on 1/2 strength of Murashige and Skoog (MS; Murashige and Skoog 1962) solid medium supplemented with $1.5 \%$ sucrose and $0.3 \%$ gelrite at $\mathrm{pH} 5.5$ under ca 2,000 lux illumination for 24 hours daily at $22^{\circ} \mathrm{C}$ after they were surface sterilized with $1 \%(\mathrm{v} / \mathrm{v})$ benzalkonium chloride for five minutes, $1-2 \%(\mathrm{v} / \mathrm{v})$ sodium hypochlorite solution for five minutes, and finally rinsed three times with distilled sterilized water. The other seeds were germinated in vivo in a compost of akadama, vermiculite, and decomposed leaves $(3: 2: 1)$ in combination in beds in the greenhouse of the laboratory. The plant species and hybrids have been preserved in the Laboratory of Plant Genetics and Breeding Research, Department of Agriculture, Faculty of Agriculture, Tokyo University of Agriculture, Funako 1737, Atsugi City, Kanagawa Prefecture, Japan.

2.3. Chromosome Preparations. Following Kondo et al. [26] growing root tips were collected and pretreated in $0.002 \mathrm{M}$ 8 -hydroxyquinoline at $18^{\circ} \mathrm{C}$ for 1.5 hours. They were fixed in the $1: 3$ of glacial acetic acid and ethanol at $4^{\circ} \mathrm{C}$ for 2 hours. Fixed roots were excised and washed in distilled water many times to remove the fixative. Five to ten tips $2-5 \mathrm{~mm}$ long each from root tips were placed in $1.5 \mathrm{~mL}$ microcentrifuge tube containing the enzymatic buffer of 5\% cellulase (Yakult), 2\% pectolyase Y-23 (Kikkoman). They were incubated at $37^{\circ} \mathrm{C}$ for 20 mins, and, then, their soft meristematic tissues were washed in distilled water to remove the enzymatic solution and were squashed in $45 \%$ acetic acid. The coverslip was removed by the dry-ice freezing method, and the preparation was dried at room temperature.

2.4. Probes Preparation and Labeling. The probe $5 \mathrm{~S}$ rDNA was produced by the polymerase chain reaction (PCR) method as described by Abd El-Twab and Kondo [20]. The probe of pTa71 (45S rDNA) consisted of a $9 \mathrm{~kb}$ Eco RI fragment of rDNA derived from Triticum aestivum L. [44], which was recloned into pUC19 plasmid. It was comprised of the coding sequence for the 18S, 5.8S, and $26 \mathrm{~S}$ genes and the nontranscribed spacer sequences. In the probe of the Arabidopsis-type telomere sequence repeats was 
synthesized by using the polymerase chain reaction (PCR). PCR was carried out in the absence of template using primers $(\text { TTTAGGG })_{5}$ and $(\text { CCCTAAA })_{5}[7,45]$. The probe of total genomic DNA: DNA was isolated from $0.5-1.0 \mathrm{~g}$ of fresh young leaf material of the two parental species following the protocol Abd El-Twab et al. [32]. Total genomic DNA of $C$. yoshinaganthum and C. vestitum was mechanically sheared and labeled with biotin 14-dATP for use as the in situ probe.

2.4.1. Labeling of the Probes. The probes were labeled either with biotin-14-dATP nick translation kit (Invitrogen) or digoxigenin (DIG)-dUTP by Dig DNA labeling kit (Roche) labeling of each probe that carried out according to the manufacturer's protocols.

2.5. The Procedure of FISH and GISH. The probe hybridization mixture ( $20 \mu \mathrm{L}$ per slide) contained about $50 \mathrm{ng}$ of each DNA-labelled probe, $10 \%$ dextran sulphate, 2X SSC, $0.25 \%$ SDS (lauryl sulphate). The probe mixtures were denatured by boiling for $5 \mathrm{~min}$, centrifuged briefly [21].

Chromosome Denaturation. The slides were denatured in a preheated formamide solution ( $70 \%$ in $2 \mathrm{X} \mathrm{SSC})$ at $72^{\circ} \mathrm{C}$ for $2 \mathrm{~min}$, dehydrated in an ice-cold ethanol series (70, 80, and $100 \%, 3$ min each), and then allowed to air-dry.

Hybridization and Washing Followed Abd El-Twab and Konodo [30]. The probe mixtures were applied to the appropriate slides and covered with glass coverslips without air bubbles. The slides were then incubated in a preheated humid chamber at $63^{\circ} \mathrm{C}$ for $2 \mathrm{~h}$ of hybridization. After gently removing the coverslips, the slides were washed for $2 \times 5 \mathrm{~min}$ in $2 \mathrm{X} \mathrm{SSC}$ at $63^{\circ} \mathrm{C}$, transferred to an incubator at $37^{\circ} \mathrm{C}$ for $20 \mathrm{~min}$, and allowed to cool to room temperature. Visualization of the hybridized probes followed Abd ElTwab et al. [43]. For double probes multicolor FISH, the yellow color was visualized by FITC after the hybridization with the biotin-labeled probes, and red color was visualized by antidigoxigenin rhodamine, and the counter stain was blue of DAPI, while the counter stain was red color of PI for single probe. The fluorescence signals were examined with an epifluorescence microscope with Nikon B-2A filter cassette, and microphotographs were taken on CCD camera (Pixera Pengium 600CL). Analysis of hybridization signals and superimposed images was produced using Adobe Photoshop 7.

\section{Results and Discussion}

We present here for the first time analytical chromosome study by FISH and GISH on the chromosome complements of interspecific $\mathrm{F}_{1}$ hybrid between $C h$. yoshinaganthum and Ch. vestitum to determine genome changes and identification of specific parental chromosomes in the artificial hybrid. Crosses between the maternal, Japanese Ch. yoshinaganthum $(2 n=36$, tetraploid), and the paternal, Chinese Ch. vestitum $(2 n=54$, hexaploid), produced fertile achenes after hand pollination which germinated and cultivated both in vitro,
TABLE 1: Crossability, seed germination, and seedling survival in $F_{1}$ hybrids between in this study.

\begin{tabular}{|c|c|}
\hline Cross combination & $\begin{array}{l}\text { Ch. Yoshinaganthum } \\
(2 n=36) \text { X Ch. } \\
\text { Vestitum }(2 n=54)\end{array}$ \\
\hline Total number of heads & 26 \\
\hline Total number of florets used & 3696 \\
\hline $\begin{array}{l}\text { Total number of fertile (aborted) achenes } \\
\text { obtained }\end{array}$ & $970(340)$ \\
\hline$\%$ fertile of achenes obtained (\%aborted) & $26.2(9.2)$ \\
\hline Total number of achenes sown in vitro & 12 \\
\hline Total number of achenes sown in vivo & 958 \\
\hline $\begin{array}{l}\text { Total number of achenes germinated in } \\
\text { vitro }\end{array}$ & 14 \\
\hline $\begin{array}{l}\text { Total number of achenes germinated in } \\
\text { vivo }\end{array}$ & 161 \\
\hline $\begin{array}{l}\text { Total number of hybrids } \\
\text { determined*/Total no. of live plants } \\
\text { studied in vitro and }(\%)\end{array}$ & $12 / 12(100 \%)$ \\
\hline $\begin{array}{l}\text { Total number of hybrids } \\
\text { determined*/Total no. of live plants } \\
\text { studied in vivo and }(\%)\end{array}$ & $74 / 74(100 \%)$ \\
\hline
\end{tabular}

and in vivo under normal condition of culture (Table 1). Among 14 plants germinated in vitro and 74 in vivo (Table 1), all plants showed true hybrids based on the leaf morphological characters with $100 \%$ hybridity. Seven plants and two from those had been grown in vivo and in vitro respectively, studied and showed the expected chromosome number of $2 n=45$ (pentaploid), of which eight plants were used for GISH (ID: y-11-4-1-1 and -10) and FISH (ID: y-11$4-1-1,-2,-5,-10,-12,-38,-45$, and -62$)$. $\mathrm{F}_{1}$ hybrids showed intermediate morphological characters of the two parents, but the hybrids resemble more closely to the hexaploid species since the leaf edge and blade inherited resemble to $C h$. vestitum, thus the hybrids used to be more closely in habit to the higher polyploid parent.

GISH applied on somatic chromosomes in the artificial interspecific $\mathrm{F}_{1}$ hybrid between Ch. yoshinaganthum and Ch. vestitum. Biotin-labeled total genomic DNA probe of $C h$. vestitum was mixed with approximately $20-40$ times blocking DNA of Ch. yoshinaganthum and applied on the somatic chromosomes. Yellow color was fluoresced and visualized by FITC and red color by PI. Approximately 18 yellowgreen colored chromosomes of $\mathrm{Ch}$. vestitum were hybridized with the probe, approximately 18 yellow-red-mixed colored chromosomes could be common chromosomes of the two species, and nine chromosomes were relatively red of Ch. yoshinaganthum that were not hybridized with the probe (Figures 1(a)-1(d); ID: y-11-4-1-10). Interphase and Prophase showed the parental chromosomes separated in two spatial domains without intermix (Figures 1(a)-1(c)). 


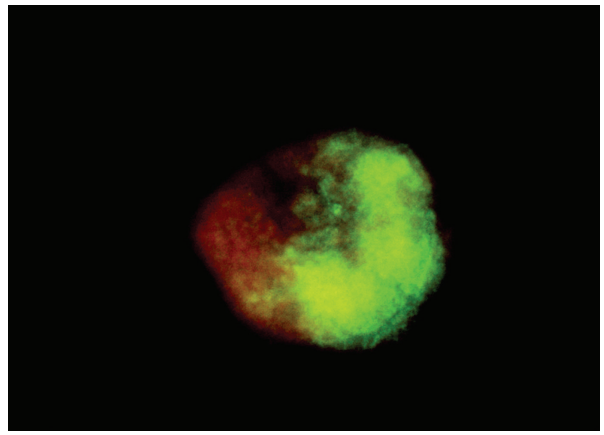

(a)

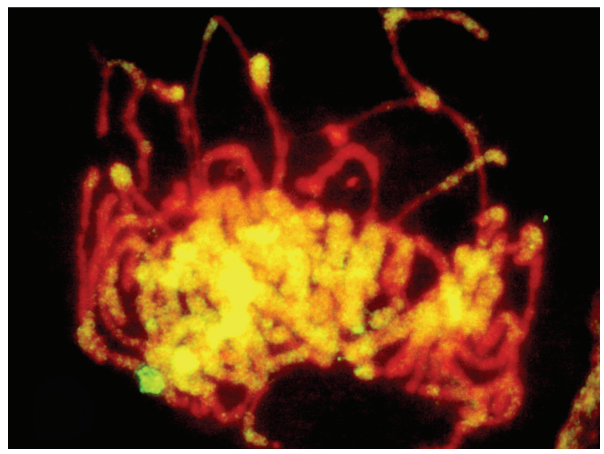

(c)

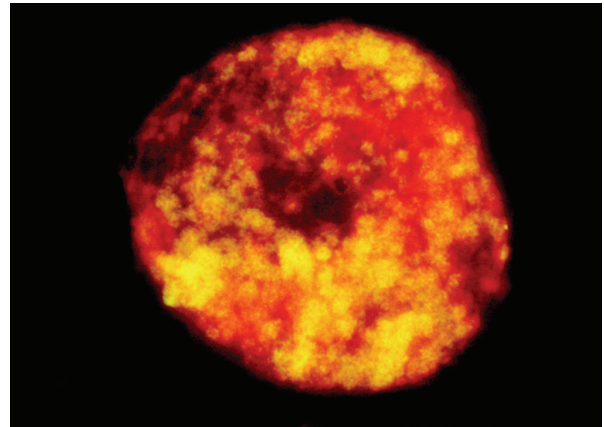

(b)

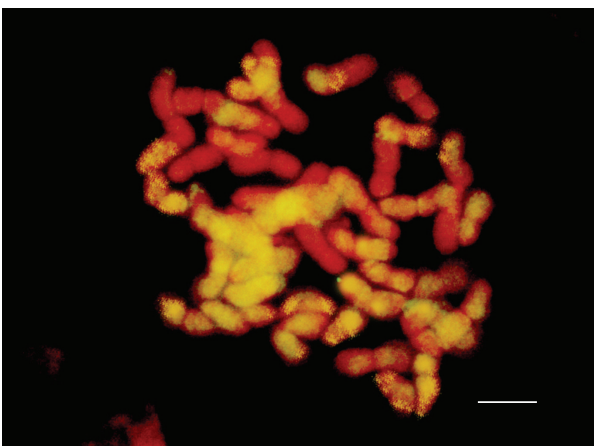

(d)

FIGURE 1: (a)-(d). GISH applied on somatic chromosomes in the artificial interspecific $\mathrm{F}_{1}$ hybrid (2n = 45, pentaploid; ID: $y$-11-4-110) between Ch. yoshinaganthum and Ch. vestitum. Biotin-labeled total genomic DNA probe of Ch. vestitum ((a)-(d)) was mixed with approximately 20-40 times blocking DNA of Ch. yoshinaganthum and used. Yellow-colored chromosomes of Ch. vestitum were hybridized with the probe and visualized by FITC, and approximately nine red-colored chromosomes of Ch. yoshinaganthum were not and stained partially red-color by PI. Interphase (a) and prophase ((b)-(c)) show the parental chromosomes separated in two spatial domains without intermix. Bar $=10 \mu \mathrm{m}$.

In the present FISH study, three probes of $5 \mathrm{~S}$ rDNA, pTa71, and telomere sequence repeats were used to investigate the genome characterization of the $\mathrm{F}_{1}$ hybrids. Multicolor FISH by applying the biotin-labeled probe of $5 \mathrm{~S}$ rDNA and digoxigenin-labeled pTa71 (Figures 2(a), 2(c), 2(e) and $2(\mathrm{f}))$ and bicolor FISH by applying biotin labeled of the telomere sequence repeats probe (Figures 2(b) and 2(d); ID: $y-11-4-1-10)$ were applied on somatic chromosomes in the artificial interspecific $F_{1}$ hybrid (Figures 2(c) and 2(f); IDs: $y$ 11-4-1-2 and y-11-4-1-5) between Ch. yoshinaganthum and Ch. vestitum. Yellow-green color of the $5 \mathrm{~S}$ rDNA loci was fluoresced and visualized by FITC, red color of the $45 \mathrm{~S}$ rDNA loci by rhodamine and whole chromosomes with blue color by DAPI. Superimposed image locates the distribution of the seven yellow-green-color signals (Figures $2(\mathrm{c})$ and $2(\mathrm{f})$ I) and 14 of the $5 \mathrm{~S}$ rDNA sites (Figures 2(e) and 2(f) II) on seven and thirteen chromosomes. Ten red signals (Figures 2(c) and 2(f) I) and 11 of the $45 \mathrm{~S}$ sites (Figures 2(e) and 2(f) II) on ten and eleven chromosomes were hybridized with the probes, respectively. The expected average of FISH six signals of $5 \mathrm{~S}$ rDNA sites and ten of $45 \mathrm{~S}$ rDNA were observed in the chromosomes of three and six plants, respectively (data not shown). Yellow-color signals of the telomeres that hybridized with the biotin-labeled telomeric probe in interphase (Figure 2(b)). All chromosomes showed terminal signals except four chromosomes showed sub-terminal sites of telomeres (Figure 2(d)).

Allopolyploidization is viewed as a highly dynamic process and a major force in the evolution of higher plants [46] and might be a source of genomic stress that facilitates rapid genome rearrangement and evolution [6, 47]. Several analyses of the constitution and interaction among the polyploid genomes in Chrysanthemum species by means of hybridization among taxa with various chromosomes numbered or high ploidy species were made (e.g. $[16,48])$. Genome rearrangement seems to be a common attribute of polyploids and still much remains unknown about polyploid plant species, including their general mode of formation [49]. The typical form of Ch. yoshinaganthum was found to have variation in chromosome number of $2 n=36$ [50] and of $2 n=72$ [51] therefore; it was proposed to have chromosome complement with more than one diploid progenitor $[5,28]$. Ch. vestitum was similar in morphology to hexaploid Japanese species regarding flower head and chromosome number, while their karyotypes were different [13] even after using fluorescent banding [52]. The autopolyploid of Ch. vestitum [13] could not be supported after fluorescent banding and FISH $[28,53]$. Natural interspecific hybrids were found in Japan and China $[14,54]$. Thus, certain introgressive hybridizations among 


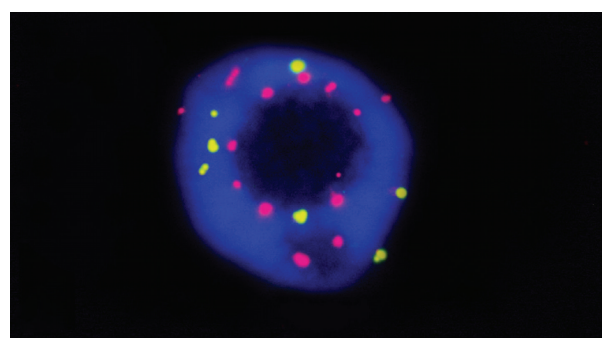

(a)

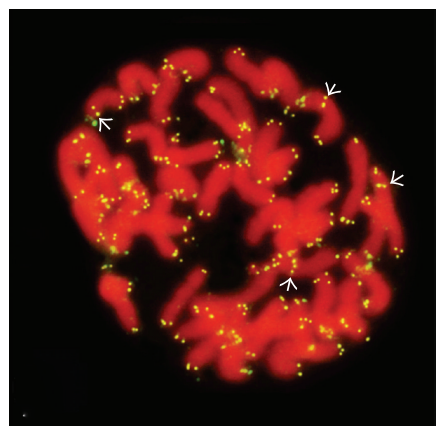

(d)

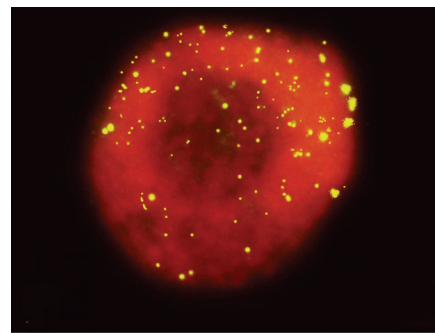

(b)

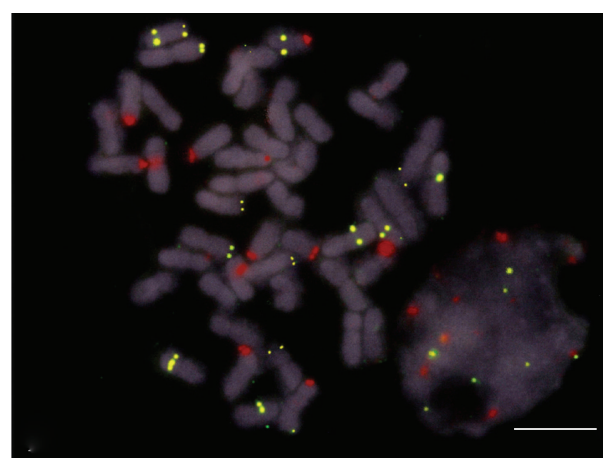

(e)

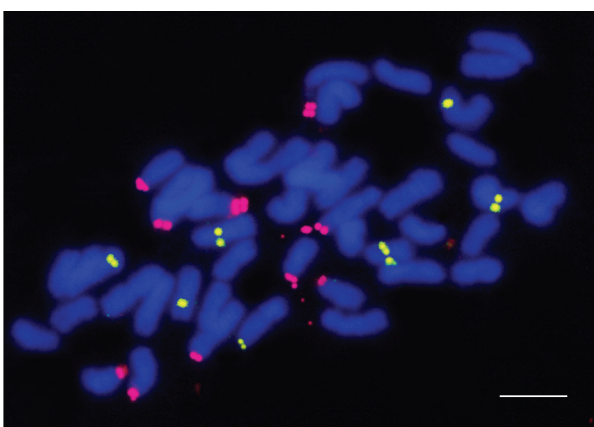

(c)

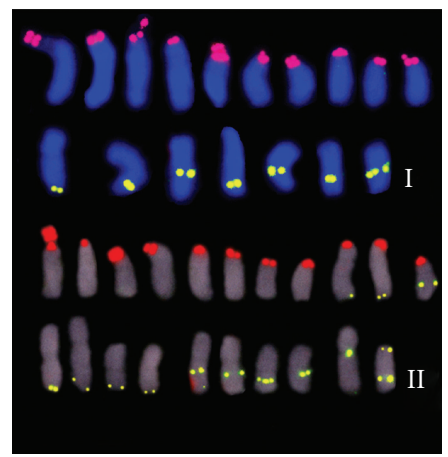

(f)

Figure 2: Tricolor FISH ((a), (c), (e), and (f).) and bicolor ((b) and (d)) applied on mitotic chromosomes in the artificial interspecific $\mathrm{F}_{1}$ hybrid between Ch. yoshinaganthum and Ch. vestitum $(2 n=45$, pentaploid, ID: y-11-4-1-10 ((b) and (d)), y-11-4-1-2 ((c) and (f) I), and y-11-4-1-5 ((e) and (f) II). (a), (c), (e), and (f). Superimposed image locates the distribution of the yellow signals of seven yellow-green-color signals ((c) and (f) I) of 5S rDNA sites and 14 ((e) and (f) II) on seven and thirteen chromosomes and ten red signals ((c) and (f) I) and 11 ((e) and (f) II) of 45S rDNA sites in ten and eleven chromosomes that were detected by the probes. (b) and (d). Yellow-color signals of the telomeres that were detected by the biotin-labeled telomeric probe in interphase (b) and terminal sites in metaphase (d). All chromosomes showed terminal signals except four chromosomes that showed subterminal sites of telomeres (pointed by four arrows). Bar $=10 \mu \mathrm{m}$.

species of Chrysanthemum might involve with differentiation and speciation among both Chinese and Japanese Chrysanthemum species. Moreover, artificial $\mathrm{F}_{1}$ hybrid between $\mathrm{Ch}$. yoshinaganthum and Ch. vestitum could be produced to perform a heptaploid plant when Ch. yoshinaganthum was used as the female parent [13]. In the present study, the chromosome number of the artificial hybrids was the average of the two parents when Ch. yoshinaganthum was used as the female parent.

The fluoresced color degree of GISH could be used for interpreting homology between the genomes and species relationships after hybridization of the labeled total genomic DNA of one of the parental probes mixed with/without blocking DNA, with the parental chromosomes of the hybrids in Chrysanthemum sensu lato $[6,17,18,21,30$, 42]. GISH applied on metaphase chromosomes of hybrid combination after using blocking DNA considered closely related [32], while other combinations considered distantly related after GISH without blocking DNA [18, 33, 41, 42]. GISH could differentiate at least 18 chromosomes of $C$. vestitum different to $C$. boreale among chromosomes of their hybrid [8]. In this study GISH coloration could support the speculation of that C. vestitum might have at least 18 chromosomes that have a different genome structure to
C. yoshinaganthum, and the other chromosomes have the common genome homology. Accordingly, C. vestitum that is geographically isolated might have different ancestor from C. yoshinaganthum, which could be color differentiated by GISH after using blocking DNA.

FISH hybridization signals of the $5 \mathrm{~S}$ and $45 \mathrm{~S}$ rDNA sites in the chromosomes of Ch. yoshinaganthum were four interstitial sites of 5S rDNA [20], while it was ten terminal sites of 45S rDNA [27] and four [31]. Ch. vestitum were eight interstitial signals of the 5S rDNA sites [20] and ten signals of the 45S rDNA [28]. Chromosome mutations could be detected in different sitespecific of $45 \mathrm{~S}$ rDNA in the chromosome complement of hybrids in Chrysanthemum sensu lato, which were resulted due to translocation and recombination indicating rapid genome changes after the artificial hybridization between C. indicum and C. vestitum as well as $C$. remotipinum and $C h$. chanetii $[6,16]$. Extra interstitial sites of $45 \mathrm{~S}$ rDNA by FISH were detected in metaphase chromosomes of the artificial intergeneric hybrid between Ch. horaimontanum and Tanacetum vulgare [9], while deletion and/or translocation of the 5SrDNA sites were detected by FISH in the chromosomes of the artificial interspecific hybrids between $C h$. remotipinum and $C h$. chanetii [16]. The present FISH data on the chromosome 
complement of the hybrid had extra one $45 \mathrm{~S}$ rDNA site and from one to eight extra 5S rDNA sites more than the mean averages of the parental chromosomal sites, as well as four interstitial translocations of the telomeric sequence repeats. The FISH physical mapping of the 5S rDNA loci was detected at terminal sites for the first time. The results imply that rapid genome changes of $F_{1}$ hybrid produced by chromosomal breakage followed by inversion recombination or translocation and inversion recombination, which might be considered an essential adjustment and required for the harmonious coexistence of the two or more different genomes in the nucleus of Chrysanthemum allopolyploids [6]. In the present study, the genome changes of chromosomal rearrangement of translocation and inversion of the present allopolyploids might be resulted soon after crossfertilization of the two gametes which were germinated and grown to healthy mature plant. Therefore, the polyploid nature of Chrysanthemum is now considered very complex. Translocation and/or inversion may not involve a loss or an addition of chromosome material, but they do become frequently associated with differences, duplications, and unbalanced combinations of genetic units [55]. Therefore, breakage inversion, translocation, recombination, and so forth, might be a reason behind the high variation in the chromosome constitution after production of allopolyploids in the artificial hybrid combinations as was observed in FISH patterns, which might be important of variation through the evolution of the species in Chrysanthemum sensu lato.

Although mutations in the chromosomes of several intergeneric combinations of the artificial hybrids produced by hand pollination $[6,7,33]$, and cell fusion [43] could be detected after the germination of the fertilized embryos in the in vitro cultures-free hormones, but also the in interspecific hybrids that germinated in vivo. Changing the number of NORs in the chromosome complements in some taxa might be due to the NORs of some chromosomes that are free to jump at least between some preferential chromosomal sites, either by means of adjacent transposable elements or due to recombination hot spots that find homologous sequences inside or proximal to the NORs [56]. Present study and others $[6,16,21]$ could detect transposition of NORs as well as $5 \mathrm{~S}$ rDNA sites to new chromosome sites through translocation of rDNA loci between homologous or nonhomologous chromosomes, or after duplication of those loci during/after direct artificial hybridization of the $F_{1}$ hybrids. Such chromosome rearrangements may be facilitated by transposable elements that can provide the substrates for recombination.

Present results and others $[6,16,42]$ imply that rapid genome changes in artificial $\mathrm{F}_{1}$ hybrids are produced by translocation/deletion and recombination, which is an essential adjustment and required for the harmonious coexistence of the two or more different genomes in the nucleus of chrysanthemum allopolyploids. Therefore, the genome changes of allopolyploids might be resulted soon after hybridization and considered as an important additional source of genetic diversity in polyploid species. The discovery of many artificial $\mathrm{F}_{1}$ hybrid combinations that have rapid genome changes in synthetic polyploids in Chrysanthemum sensu lato provides a new avenue of investigation into the molecular cytogenetics events, which shape the outcome of allopolyploidy. It seems that the synthetic polyploid has the adaptive function of stabilizing genotype through mutations, which might possess an adaptive advantage to various new environments.

\section{Acknowledgments}

This study was supported by the Grant-in-Aid for Scientific Research Program (A) no. 10044209 of Japan Society for the Promotion of Science (Representative: Katsuhiko Kondo) and the National Bioresource Project "Chrysanthemum sensu lato" of the Japanese Ministry of Education, Science, Sports and Culture (Representative: Katsuhiko Kondo). "Memory of chromosome researches in the Anthemideae, Asteraceae and retirement to Prof. Joan Valles, Barcerona University, Spain."

\section{References}

[1] K. Kondo, R. Tanaka, D. Hong, M. Hizume, Q. Yang, and M. Nkata, "A chromosome study of Ajania and its allied genera in the Chrysantheminae, the Anthemideae, the Compositae in Chinese highlands," in Karyomorphological and Cytogenetical Studies in Plants Common to Japan and China, R. Tanaka, Ed., pp. 1-13, Hiroshima University, 1994.

[2] K. Kondo, R. Tanaka, S. Ge, D. Hong, and M. Nakata, "Chromosome studies of Ajania and its alied genera," in Compositae: Systematics. Prooceeding of the International Compositae Conference, D. J. N. Hind and H. J. Beentje, Eds., vol. 1, pp. 425434, Royal Botanic Gardens, Kew, NY, USA, 1994.

[3] M. H. Abd El-Twab and K. Kondo, "Physical mapping of 5S, 45S, Arabidopsis-type telomere sequence repeats and AT-rich regions in Achillea millefolium showing intrachromosomal variation by FISH and DAPI," Chromosome Botany, vol. 4, pp. 37-45, 2009.

[4] M. Ørgaard and J. S. Heslop-Harrison, "Investigations of genome relationships between Leymus, Psathyrostachys and Hordeum inferred by genomic DNA:DNA in situ hybridization," Annals of Botany, vol. 73, no. 2, pp. 195-203, 1994.

[5] K. Kondo and M. H. Abd El-Twab, "Analysis of intera-generic relationships Sensu stricto among the members of Chrysanthemum sensu lato by using fluorescence in situ hybridization and genomic in situ hybridization," Chromosome Science, vol. 6, pp. 87-100, 2002.

[6] M. H. Abd El-Twab and K. Kondo, "Rapid genome reshuffling induced by allopolyploidy in $\mathrm{F}_{1}$ hybrid in Chrysanthemum remotipinum (formerly Ajania remotipinna) and Chrysanthemum chanetii (formerly Dendranthema chanetii)," Chromosome Botany, vol. 2, pp. 1-9, 2007.

[7] M. H. Abd El-Twab and K. Kondo, "FISH physical mapping of $5 \mathrm{~S}$ rDNA and telomere sequence repeats identified a peculiar chromosome mapping and mutation in Leucanthemella linearis and Nipponanthemum nipponicum in Chrysanthemum sensu lato," Chromosome Botany, vol. 2, pp. 11-17, 2007.

[8] M. H. Abd El-Twab and K. Kondo, "Isolation of chromosomes and mutation in the interspecific hybrid between Chrysanthemum boreale and Ch. vestitum using fluorescence in situ hybridization and genomic in situ hybridization," Chromosome Botany, vol. 2, pp. 19-24, 2007. 
[9] M. H. Abd El-Twab and K. Kondo, "Identification of parental chromosomes, intra-chromosomal changes and relationship of the artificial intergeneric hybrid between Chrysanthemum horaimontanum and Tanacetum vulgare by single color and simultaneous bicolor of FISH and GISH," Chromosome Botany, vol. 2, pp. 113-119, 2007.

[10] K. Wolff and J. Peters-van Rijn, "Rapid detection of genetic variability in chrysanthemum (Dendranthema grandiflora Tzvelev) using random primers," Heredity, vol. 71, p. 4, 1993.

[11] R. Tanaka, M. Nakata, and M. Aoyama, "Cytogenetic studies on wild Chrysanthemum from China IV. Karyotype of Ch. morii," Chromosome Information Service, vol. 43, pp. 18-19, 1987.

[12] R. Tanaka, S. Kawasaki, Y. Yonezawa, K. Taniguchi, and H. Ikeda, "Cytogenetic studies on wild Chrysanthemum from China V. F1-hybrids of Chrysanthemum lavandulifolium var. sianense X Ch. boreale," Cytologia, vol. 54, pp. 365-372, 1989.

[13] M. Nakata, D. Hong, J. Qiu, H. Uchiyama, R. Tanaka, and S. Chen, "Cytogenetic studies on wild Chrysanthemum sensu lato in China. I. Karyotype of Dendranthema vestitum," Japanese Journal of Botany, vol. 66, pp. 199-204, 1991.

[14] M. Nakata, D. Hong, J. Qiu, H. Uchiyama, R. Tanaka, and S. Chen, "Cytogenetic studies on wild Chrysanthemum sensu lato in China. II. A natural hybrid between Dendranthema indicum $(2 n=36)$ and $D$. vestitum $(2 n=54)$ from Hbei Province," Japanese Journal of Botany, vol. 67, pp. 92-100, 1992.

[15] K. Kondo, R. Tanaka, S. Ge, D. Hong, and M. Nakata, "Cytogenetic studies on wild Chrysanthemum sensu lato in China. IV. Karyomorphological characteristics of three species of Ajania," Japanese Journal of Botany, vol. 67, pp. 324-329, 1992.

[16] M. H. Abd El-Twab and K. Kondo, "Rapid genome changes after inter specific hybridization between Dendranthema indica $X D$. vestita identified by fluorescent in situ hybridization and 4, 6-diamidino-2-phenylindole," Chromosome Science, vol. 7, pp. 77-81, 2003.

[17] M. H. Abd El-Twab and K. Kondo, "Discrimination and isolation of terminal chromosomal regions of Dendranthema occidentali-japonense in the chromosomes of $\mathrm{F}_{1}$ hybrid of Dendranthema boreale by using GISH," Chromosome Science, vol. 4, pp. 87-93, 2000.

[18] M. H. Abd El-Twab and K. Kondo, "Molecular cytogenetic identification of the parental genomes in the intergeneric hybrid between Leucanthemella linearis and Nipponanthemum nipponicum during meiosis and mitosis," Caryologia, vol. 54, no. 2, pp. 109-114, 2001.

[19] J. Inafuku, M. Nabeyama, Y. Kikuma, J. Saitoh, S. Kubota, and S. I. Kohno, "Chromosomal location and nucleotide sequences of $5 \mathrm{~S}$ ribosomal DNA of two cyprinid species (Osteichthyes, Pisces)," Chromosome Research, vol. 8, no. 3, pp. 193-199, 2000.

[20] M. H. Abd El-Twab and K. Kondo, "Physical mapping of 5S rDNA in chromosomes of Dendranthema by fluorescence in situ hybridization," Chromosome Science, vol. 6, pp. 13-16, 2002.

[21] M. H. Abd El-Twab and K. Kondo, "Identification of mutation and homologous chromosomes in four cultivars of Dendranthema grandiflora by physical mapping of 5S and 45S rDNA using fluorescence genomic in situ hybridization," Chromosome Science, vol. 8, pp. 81-68, 2004.

[22] M. H. Abd El-Twab and K. Kondo, "FISH physical mapping of 5S, 45S and Arabidopsis-type telomere sequence repeats in Chrysanthemum zawadskii showing intra-chromosomal variation and complexity in nature," Chromosome Botany, vol. 1, pp. 1-5, 2006.
[23] J. Fuchs and I. Schubert, "Localization of seed protein genes on metaphase chromosomes of Vicia faba via fluorescence in situ hybridization," Chromosome Research, vol. 3, no. 2, pp. 94100, 1995.

[24] G. E. Harrison and J. S. Heslop Harrison, "Centromeric repetitive DNA sequences in the genus Brassica," Theoretical and Applied Genetics, vol. 90, no. 2, pp. 157-165, 1995.

[25] J. S. Heslop-Harrison, T. Schwarzacher, K. AnamthawatJonson, A. R. Leich, M. Shi, and I. J. Leich, "In situ hybridization with automated chromosome denaturation," Technique, vol. 3, pp. 109-116, 1991.

[26] K. Kondo, Y. Honda, and R. Tanaka, "Chromosome marking in Dendranthema japonica var. wakasaense and its closely related species by fluorescence in situ hybridization using rDNA probe.," La Kromosomo, vol. 81, pp. 2785-2791, 1996.

[27] K. Khaung, K. Kondo, and R. Tanaka, "Physical mapping of rDNA by fluorescent in situ hybridization using pTa71 probe in three tetraploid species of Dendranthema," Chromosome Science, vol. 1, pp. 25-30, 1997.

[28] M. H. Abd El-Twab and K. Kondo, "Physical mapping of 45S rDNA loci by fluorescent in situ hybridization and Evolution among polyploid Dendranthema species," Chromosome Science, vol. 7, pp. 71-76, 2003.

[29] S. P. Adams, I. J. Leitch, M. D. Bennett, M. W. Chase, and A. R. Leitch, "Ribosomal DNA evolution and phylogeny in Aloe (Asphodelaceae)," American Journal of Botany, vol. 87, no. 11, pp. 1578-1583, 2000.

[30] M. H. Abd El-Twab and K. Kondo, "Fluorescence in situ hybridization and genomic in situ hybridization to identify the parental genomes in the intergeneric hybrid between Chrysanthemum japonicum and Nipponanthemum nipponicum," Chromosome Botany, vol. 1, pp. 7-11, 2006.

[31] Y. Honda, M. H. Abd El-Twab, H. Ogura, K. Kondo, R. Tanaka, and T. Shidahara, "Counting sat-chromosome numbers and species characterization in wild species of Chrysanthemum sensu lato by fluorescence in situ hybridization using pTa71 probe," Chromosome Science, vol. 1, pp. 77-81, 1997.

[32] M. H. Abd El-Twab, K. Kondo, and D. Hong, "Isolation of a particular chromosome of Ajania remotipinna in a chromosome complement of an artificial $\mathrm{F}_{1}$ hybrid of Dendranthema lavandulifolia X Ajania remotipinna by use of genomic in situ hybridization," Chromosome Science, vol. 3, pp. 21-28, 1999.

[33] M. H. Abd El-Twab and K. Kondo, "Identification of nucleolar organizing regions and parental chromosomes in $\mathrm{F}_{1}$ hybrid of Dendranthema japonica and Tanacetum vulgare simultaneously by fluorescence in situ hybridization," Chromosome Science, vol. 3, pp. 59-62, 1999.

[34] M. H. Abd El-Twab and K. Kondo, "Visualization of genomic relationships in allotetraploid hybrids between Chrysanthemum lavandulifolium X Ch. chanetii by fluorescence in situ hybridization and genomic in situ hybridizarion," Chromosome Botany, vol. 3, pp. 19-25, 2008.

[35] T. Schwarzacher, A. R. Leitch, M. D. Bennett, and J. S. Heslopharrison, "In Situ localization of parental genomes in a wide hybrid," Annals of Botany, vol. 64, no. 3, pp. 315-324, 1989.

[36] K. Anamthawat-Jónsson, T. Schwarzacher, A. R. Leitch, M. D. Bennett, and J. S. Heslop-Harrison, "Discrimination between closely related Triticeae species using genomic DNA as a probe," Theoretical and Applied Genetics, vol. 79, no. 6, pp. 721-728, 1990.

[37] S. T. Bennett, A. Y. Kenton, and M. D. Bennett, "Genomic in situ hybridization reveals the allopolyploid nature of Milium montianum (Gramineae)," Chromosoma, vol. 101, no. 7, pp. 420-424, 1992. 
[38] A. S. Parokonny, A. Kenton, Y. Y. Gleba, and M. D. Bennett, "The fate of recombinant chromosomes and genome interaction in Nicotiana asymmetric somatic hybrids and their sexual progeny," Theoretical and Applied Genetics, vol. 89, no. 4, pp. 488-497, 1994.

[39] Chen Qin, R. L. Conner, and A. Laroche, "Identification of the parental chromosomes of the wheat-alien amphiploid Agrotana by genomic in situ hybridization," Genome, vol. 38, no. 6, pp. 1163-1169, 1995.

[40] C. Takahashi, I. J. Leitch, A. Ryan, M. D. Bennett, and P. E. Brandham, "The use of genomic in situ hybridization (GISH) to show transmission of recombinant chromosomes by a partially fertile bigeneric hybrid, Gasteria lutzii X Aloe aristata (Aloaceae), to its progeny," Chromosoma, vol. 105, no. 6, pp. 342-348, 1996.

[41] H. Ogura and K. Kondo, "Application of genomic in situ hybridization to the chromosome complement of the intergeneric hybrid between Leucanthemella linearis (Matsum.) Tzuvelev and Nipponanthemum nipponicum (Franch.et Maxim.) Kitamura," Chromosome Science, vol. 2, pp. 91-93, 1998.

[42] K. Kondo, M. H. Abd El-Twab, and R. Tanaka, "Fluorescence in situ hybridization identifies reciprocal translocation of somatic chromosomes and origin of extra chromosome by an artificial, intergeneric hybrid between Dendranthema japonica X Tanacetum vulgare," Chromosome Science, vol. 3, pp. 15-19, 1999.

[43] M. H. Abd El-Twab, H. Shinoyama, and K. Kondo, "Evidences of intergeneric somatic-hybrids between Dendranthema grandiflora cv. Shuho-no-chikara and Artemisia sieversiana and their chromosomal mutations by using fluorescence in situ hybridization and genomic in situ hybridization," Chromosome Science, vol. 8, pp. 29-34, 2004.

[44] W. L. Gerlach and J. R. Bedbrook, "Cloning and characterization of ribosomal RNA genes from wheat and barley," Nucleic Acids Research, vol. 7, no. 7, pp. 1869-1885, 1979.

[45] A. V. Cox, S. T. Bennett, A. S. Parokonny, A. Kenton, M. A. Callimassia, and M. D. Bennett, "Comparison of plant telomere locations using a PCR-generated synthetic probe," Annals of Botany, vol. 72, no. 3, pp. 239-247, 1993.

[46] P. S. Soltis and D. E. Soltis, "The role of genetic and genomic attributes in the success of polyploids," Proceedings of the National Academy of Sciences of the United States of America, vol. 97, no. 13, pp. 7051-7057, 2000.

[47] X. P. Zhao, Y. Si, R. E. Hanson et al., "Dispersed repetitive DNA has spread to new genomes since polyploid formation in cotton," Genome Research, vol. 8, no. 5, pp. 479-492, 1998.

[48] N. Shimotomai, "Zurkaryogentik der gattung Chrysanthemum," Journal of Science, Hiroshima University, Series B, vol. 2, pp. 1-100, 1933.

[49] B. S. Gaut, M. L. T. D’Ennequin, A. S. Peek, and M. C. Sawkins, "Maize as a model for the evolution of plant nuclear genomes," Proceedings of the National Academy of Sciences of the United States of America, vol. 97, no. 13, pp. 7008-7015, 2000.

[50] R. Tanaka, "On the speciation and karyotypes in diploid and tetraploid species of Chrysanthemum yoshinaganthum $(2 n=$ 36)," Cytologia, vol. 25, pp. 43-58, 1960.

[51] S. Fukai, Y. Kamigaichi, N. Yamasaki, W. Zhang, and M. Goi, "Distribution, morphological variations and cpDNA PCRRFLP analysis of Dendranthema yoshinaganthum," Journal of the Japanese Society for Horticultural Science, vol. 71, no. 1, pp. 114-122, 2002.
[52] K. Kondo, K. K. Khaung, R. Tanaka, and M. Nakata, "Fluorescent banding patterns in hexaploid Dendranthema occidentalijaponense and D. vestitum," La Kromosomo, vol. 70-80, pp. 2739-2745, 1995.

[53] K. K. Khaung, Species relationships of the polyploid Dendranthema, sec. Dendranthema (the Chrysantheminae, the Anthemideae, the Compositae), A thesis, School of Science, Hiroshima University, 1997.

[54] M. Nakata, "Possible natural hybrids with chromosome $2 n=$ 62 between Chrysanthemum wakasaense and C. morifolium," Bulletin National of Science Museum, Tokyo, Series B, vol. 15, pp. 143-149, 1989.

[55] E. J. Gardner, M. J. Simmons, and D. P. Snustad, "Variations in Chromosome Structure," in Principles of Genetics, chapter 18, pp. 488-510, John Wiley \& Sons, New York, NY, USA, 8th edition, 1984.

[56] I. Schubert and U. Wobus, "In situ hybridization confirms jumping nucleolus organizing regions in Allium," Chromosoma, vol. 92, no. 2, pp. 143-148, 1985. 

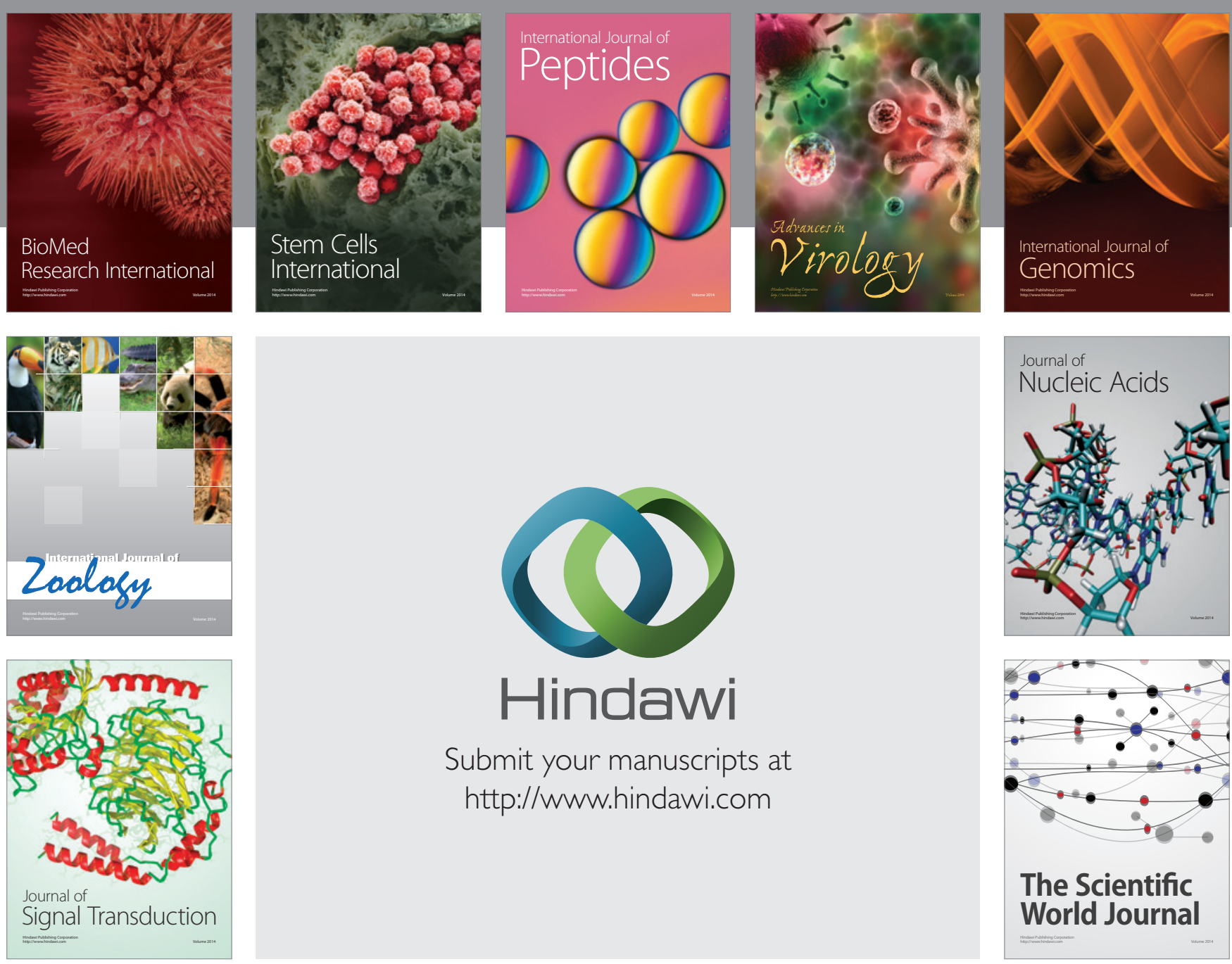

Submit your manuscripts at

http://www.hindawi.com
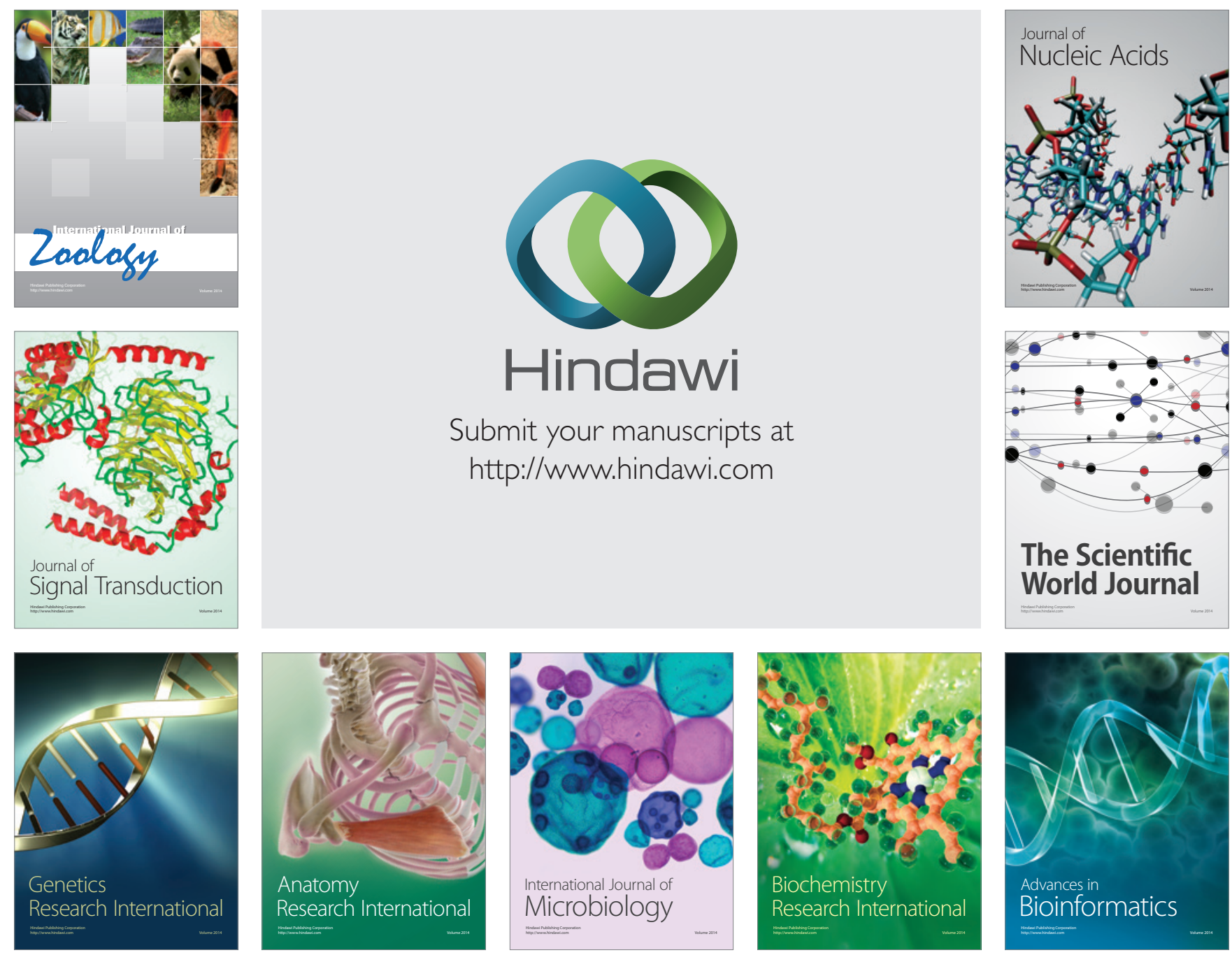

The Scientific World Journal
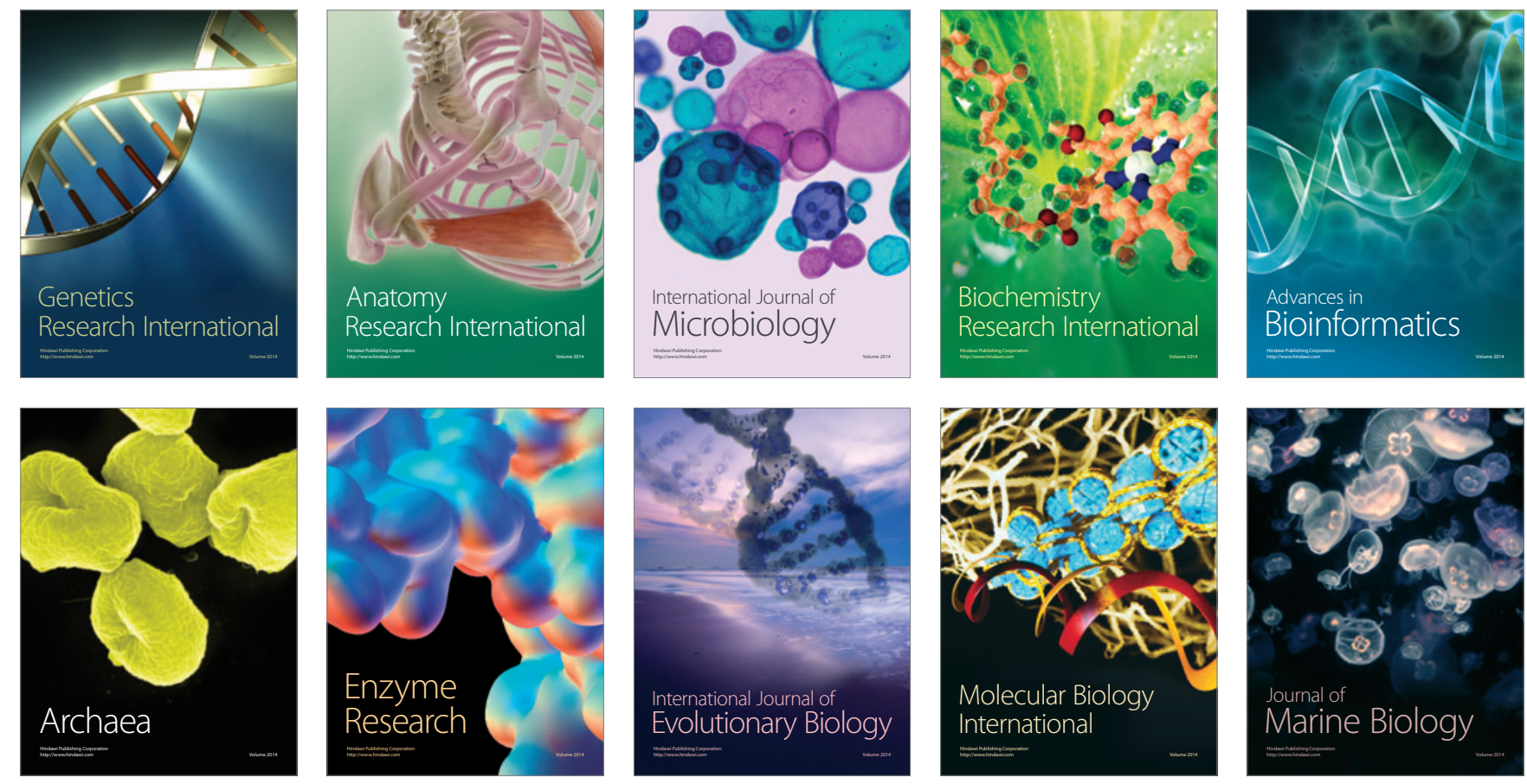